\title{
Abnormalities of Carbohydrate Metabolism in Idiopathic Fanconi Syndrome
}

\author{
RUSSELL W. CHESNEY, ${ }^{(45)}$ BERNARD S. KAPLAN, ELEANOR COLLE, CHARLES R. SCRIVER, \\ RODERICK R. MCINNES, CLAIRE H. DUPONT, AND KEITH N. DRUMMOND \\ Department of Pediatrics, University of Wisconsin, Madison, Wisconsin, USA; and Departments of Pediatrics, \\ Nephrology, Endocrinology, and Biochemical Genetics, Montreal Children's Hospital-McGill University Research \\ Institute, Montreal, Quebec, Canada
}

\begin{abstract}
Summary
Various metabolic studies were performed in a patient with the idiopathic Fanconi syndrome in whom constant ketonuria suggested that organic acidemia might contribute to the metabolic acidosis. Glucose intolerance with a diminished insulin release was found after PO or IV glucose loads and after glucagon administration. An insulinopenic "diabetes-like" state has not previously been described in such patients. The patient had impaired galactose-glucose interconversion, elevated blood lactate levels, reduced pyruvate levels, and an increased lactate:pyruvate ratio. Hepatomegaly and hypoglycemia were not present, and liver and muscle biopsies revealed no enzymatic evidence of glycogenosis. The erythrocyte UDP galactose transferase activity was normal.

The patient failed to convert fructose to glucose and had a rise in blood lactate after ethanol administration. Further studies revealed no production of glucose after alanine or glycerol administration, each test being associated with elevated blood lactate levels and, after alanine, an increased lactate:pyruvate ratio. The lactate:pyruvate ratio was elevated after glucagon administration with increased lactate and reduced pyruvate concentrations.
\end{abstract}

\section{Speculation}

The increased lactate:pyruvate ratio, abnormal galactose-glucose, and pyruvate-lactate interconversions suggest an altered intracellular redox state with an abnormally high NADH:NAD ${ }^{+}$ ratio.

\section{INTRODUCTION}

The Fanconi syndrome of proximal renal tubular dysfunction is characterized clinically by growth retardation and rickets and biochemically by aminoaciduria, glucosuria, phosphaturia (with hypophosphatemia), and bicarbonaturia (with hyperchloremic metabolic acidosis). The syndrome may be idiopathic or secondary to a variety of conditions which include cystinosis, galactosemia, and tyrosinosis. Idiopathic Fanconi syndrome can occur sporadically, or it may be inherited by an autosomal recessive or dominant modes. A diagnosis of idiopathic Fanconi syndrome can only be made after exclusion of the known causes of the syndrome (33). Features of proximal renal tubular acidosis as it occurs in Fanconi syndrome are bicarbonaturia, hyperchloremic metabolic acidosis, normal or decreased concentrations of undetermined anion, and a urine $\mathrm{pH}$ that is inappropriately alkaline as long as the serum bicarbonate concentration is above the patient's tubular reabsorptive capacity for bicarbonate $(19,24,29)$. This patient differed from most but not all $(17,20,23)$ cases hitherto reported with idiopathic Fanconi syndrome in that the metabolic acidosis was often associated with an increase in the level of undetermined anions, and ketonuria was almost always detected. In addition, she also had a markedly abnormal glucose response to exogenous insulin and no insulin response to glucose infusion.
These findings led to a study of carbohydrate metabolism and a search for a possible enzyme deficiency which could account for the observed abnormalities. Therefore, the purpose of this paper is to describe the abnormalities in carbohydrate metabolism which could be demonstrated in this patient. These most closely resemble those described in patients with Fanconi syndrome, hepatic glycogenosis, and normal glucose-6-phosphatase activity $(8,17)$.

\section{CASE REPORT}

V. P. was 6 years old when the metabolic studies were done. She had vomiting and hypoglycemia in the neonatal period, but was first seen at the Montreal Children's Hospital at 18 months of age. She was extremely hypotonic, and all anthropomorphic measurements were below the 3rd percentiles for age. The parents were not consanguinous; the mother was well, and the father could not be studied. There were no siblings, and no family history of features suggestive of the Fanconi syndrome.

A diagnosis of Fanconi syndrome was based on the following observations: glucosuria (greater than 3 g glucose excreted per 24 $\mathrm{hr}$ ), a generalized aminoaciduria (the alanine spot was consistently prominant), hypophosphatemia. $2.4 \mathrm{mg} / \mathrm{dl}$, a reduced tubular reabsorption of phosphate of $22 \%$, a hyperchloremic metabolic acidosis with a serum chloride concentration of $116 \mathrm{mEq} / \mathrm{liter}$, serum bicarbonate level of $14 \mathrm{mEq} /$ liter, inappropriate urine $\mathrm{pH}$ of 8 at serum bicarbonate of $20 \mathrm{mEq} /$ liter, and marked radiologic evidence of rickets and osteoporosis. The causes of Fanconi syndrome that could be excluded are shown in Table 1 .

Hypophosphatemia and rickets were treated with $P O$ phosphate provided as Neutrophos, 1 to $4 \mathrm{~g} /$ day in 5 doses. Dihydrotachysterol was given in a dose of $0.25 \mathrm{mg} /$ day. The acidosis was treated with Shol's solution which provided 10 to $15 \mathrm{mEq} / \mathrm{kg} /$ day of buffer. On this regimen, the rickets healed, the serum phosphate concentration was maintained at 3.5 to $4.5 \mathrm{mg} / \mathrm{dl}$, and the serum bicarbonate varied between 18 and $22 \mathrm{mEq} /$ liter.

She also had ketonuria but ketones could not be detected after she was started on a diet supplemented every few hr with glucose.

\section{METHODS}

Informed consent was obtained for the tolerance tests which were done in the Clinical Investigation Unit of the Montreal Children's Hospital. The studies were done after 15- to 18-hr fasts during which only water, sodium bicarbonate, and phosphate were allowed. The acid-base status and serum potassium and phosphate concentrations were normal during the studies.

Samples of blood obtained from an indwelling venous catheter were kept in heparinized tubes. Free-flowing blood rapidly deproteinized with chilled perchloric acid was used for lactate and pyruvate determinations.

Substances administered PO were glucose, $1.5 \mathrm{~g} / \mathrm{kg}$, galactose, $1.75 \mathrm{~g} / \mathrm{kg}$, fructose, $1.5 \mathrm{~g} / \mathrm{kg}$, and ethanol, $0.7 \mathrm{ml} / \mathrm{kg}$. Insulin was infused at a rate of 0.05 units $/ \mathrm{kg}$. 
Table 1. Evaluation of secondary causes of the Fanconi syndrome in the patient

Cystinosis:

Galactosemia:

Fructosemia:

Tyrosinemia:

Macroglobulinemia:

Wilson's disease:

Hepatic

glycogenosis:

Lead, cadmium tetracy clines:

Malabsorption

syndromes:

Liver disease

Chronic interstitial nephritis:
Leukocyte cystine level less than $0.18 \mu \mathrm{M}$ / g protein; normal slit lamp examination (33).

Urine negative for galactose; thin-layer chromatographic analysis of media from patient's leukocytes incubated in 14C-Dgalactose demonstrated normal conversion to galactose-1-phosphate. UDP galactose, and normal ratios of these 3 compounds (36).

Urine negative for fructose. No fall in serum $\mathrm{PO}_{4}$ after a fructose load.

Normal plasma tyrosine level of 26 $\mu$ moles/liter.

Negative.

Normal serum ceruloplasmin level of 30 $\mathrm{mg} / \mathrm{dl}$.

No hypoglycemia, hyperuricacidemia, or hepatomegaly. Normal glucose-6-phosphatase level in liver biopsy.

No history of exposure.

Normal carotene and vitamin A levels.

No jaundice or elevated hepatic enzyme values.

Urinalysis normal. No azotemia at onset of disease.
In addition glycerol, $140 \mathrm{mmoles} / \mathrm{sq} \mathrm{m}$ (37) and alanine, 5.5 mmoles/kg (27), were given PO. Glucagon, $1 \mathrm{mg}$, was administered IM in the fasted and fed state.

Lactate and pyruvate were measured in whole blood by an enzymatic method (31). True glucose concentration was analyzed by a glucose oxidase method in a Beckman glucose analyzer. Total aldosugars were determined by an orthotoluidine colorimetric assay (15). Total reducing substances including fructose and glucose were measured by ferricyanate reduction (13). Free fatty acid concentrations were assayed by a colorimetric microassay (18). All plasma and urine samples for organic and amino acids were stored at $-70^{\circ} \mathrm{C}$ until analyzed. Protein-free filtrates of plasma were used for amino acid measurements which were determined by column chromatography in a Beckman amino acid analyzer $(26,34)$. Organic acids were identified by gas liquid chromatography-mass spectroscopy (22). Urine ketones were detected by reaction with 2,4-dinitrophenylhydrazine (35). Urine amino acids were examined by two-dimensional partition chromatography (5). Plasma insulin and glucagon concentrations were determined by a radioimmunoassay method (12). Leukocytes were isolated in a $6 \%$ dextran and heparin gradient (4), and leukocyte cystine levels were determined on cell lysates (9). Fructose-1,6-diphosphatase activity was assayed in the leukocytes of patient and controls (25). The following enzyme activities were measured in homogenates of liver and skeletal muscle: glucose-6-phosphatase (11), phosphoglucomutase, phosphorylase with and without AMP, $\beta$-glucosidase, lactic dehydrogenase, $\alpha-1,6$-glucosidase, and creatinine phosphokinase (30). Glycogen content was determined in liver and muscle specimens (11). The activity of galactokinase and UDP galactose transferase was determined by a thin-layer chromatographic assay (36).
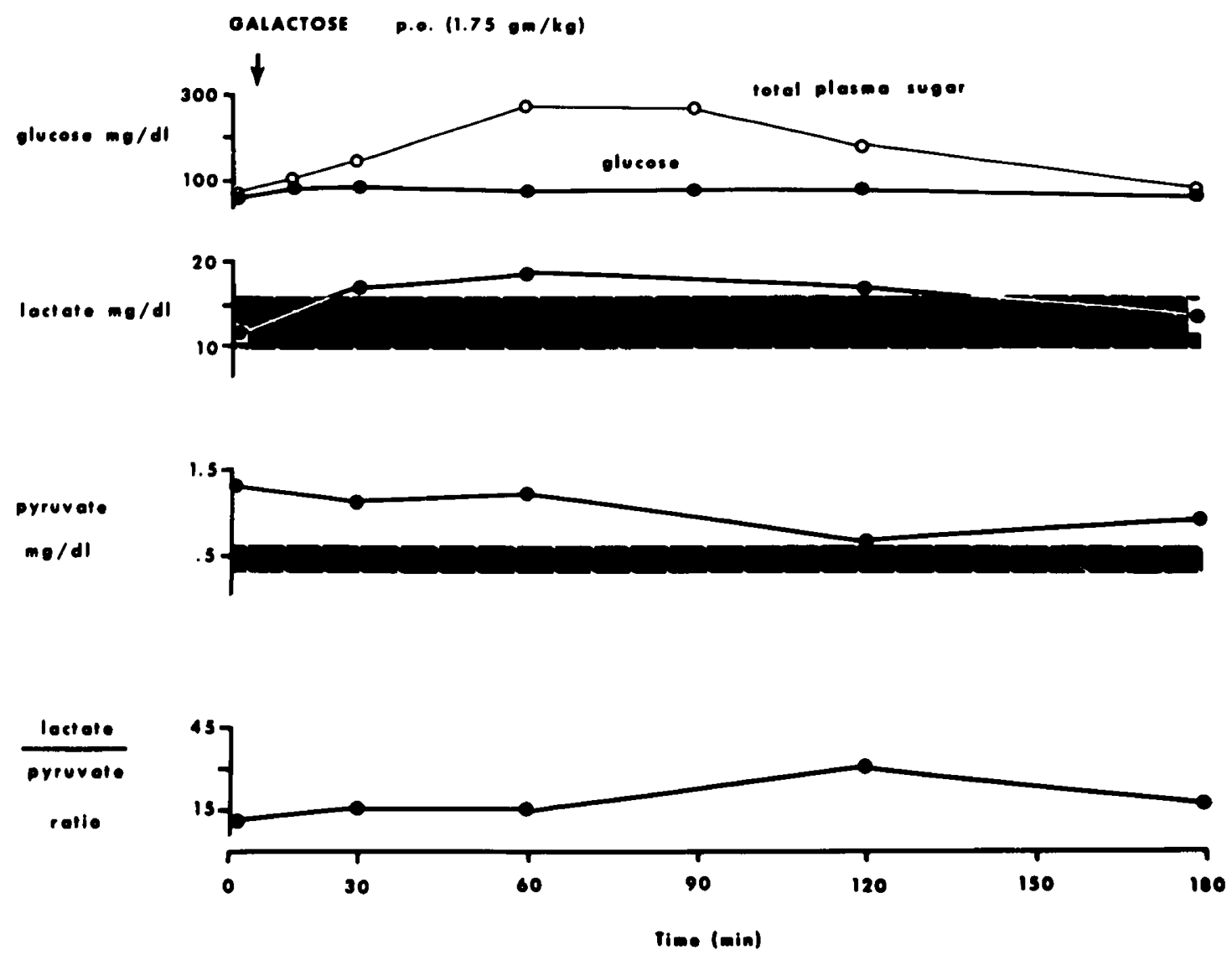

Fig. 1. Galactose PO was given after an overnight fast $(1.75 \mathrm{~g} / \mathrm{kg})$, and blood or plasma samples were obtained for $120 \mathrm{~min}$. The upper portion of the curve displays the values for aldosugars $(\mathrm{mg} / \mathrm{dl})$ measured by an $O$ toluidine method and true glocose $(\mathrm{mg} / \mathrm{dl})$ measured by the glucose

oxidase method. The second portion depicts the blood lactate $(\mathrm{mg} / \mathrm{dl})$. Cross-hatched area, normal range. The third portion displays the blood pyruvate levels (mg/dl), and the cross-hatched area, normal values. Lowest portion, $\mathrm{L}: \mathrm{P}$ ratio. The normal value is from $5: 1$ to $15: 1$. 


\section{RESULTS}

The patient had persistent ketonuria and plasma lactate levels higher than $1.7 \mathrm{mM} /$ liter (range, 1.7 to $4.0 \mathrm{mM} /$ liter) on her usual diet. A prominent alanine spot was found in all urine aminoacid chromatograms despite normal plasma alanine levels of 300 to $360 \mu \mathrm{moles} / \mathrm{liter}$ (normal, 280 to $400 \mu$ moles/liter).

\section{GLUCOSE LOADING TEST}

After an 18-hr fast, the plasma glucose level was $84 \mathrm{mg} / \mathrm{dl}$. There were ketonuria and ketonemia. Insulin release was always less than 6 microunits $/ \mathrm{ml}$ which is the lower level of sensitivity for the assay.

Glucose IV $(2.0 \mathrm{~g} / \mathrm{kg})$ resulted in a peak glucose value of 408 $\mathrm{mg} / \mathrm{dl}$ with negligible insulin secretion. Massive glucosuria was present, and the major organic acids in 4 urine samples were acetoacetate, $\beta$-hydroxybutyrate, lactate, and pyruvate. The ratio of $\beta$-hydroxybutyrate to acetoacetate ranged from $13: 1$ to $77: 1$. No other organic acids were identified.

\section{GALACTOSE LOADING TEST}

Following PO galactose, the peak plasma aldosugar (glucose and galactose) level was $303 \mathrm{mg} / \mathrm{dl}$, but there was no rise in true glucose levels (Fig. 1). The insulin levels were less than 6 microunits $/ \mathrm{ml}$. The lactate:pyruvate (L:P) ratio was increased, blood lactate levels were elevated, and pyruvate levels were normal or decreased. Galactose appeared in the urine only after galactose was given. Galactokinase and UDP galactose transferase activities were normal in the erythrocytes.

\section{RESPONSE TO EXOGENOUS INSULIN}

Administration IV of exogenous aqueous insulin (0.05 units/ $\mathrm{kg}$ ) produced a fall in blood glucose levels from 84 to $23 \mathrm{mg} / \mathrm{dl}$.
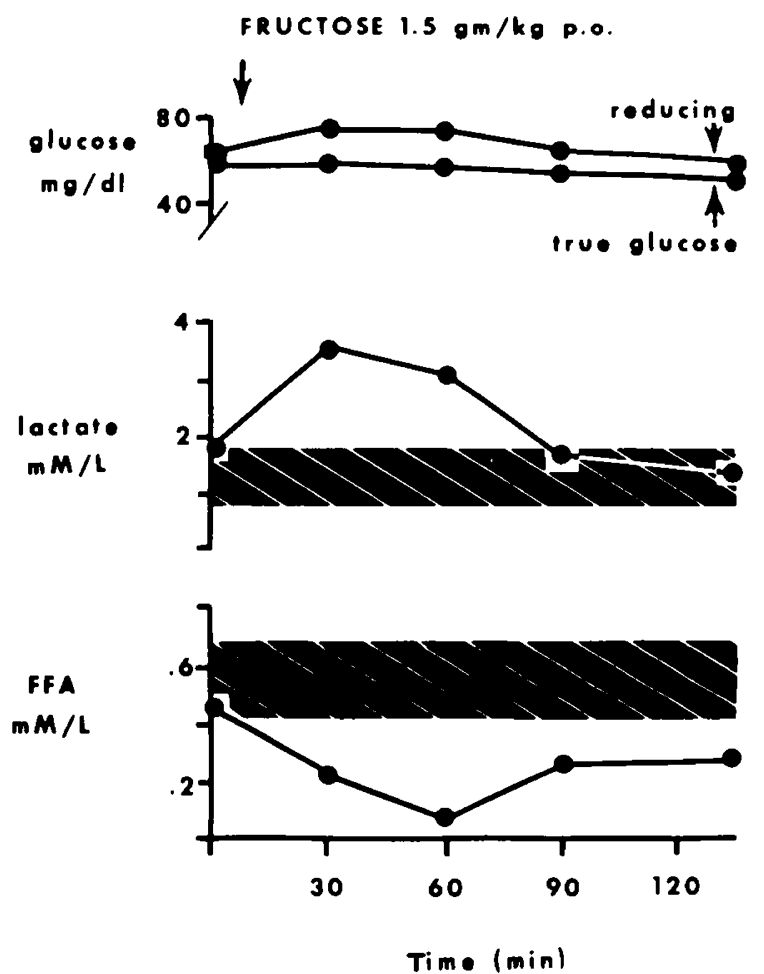

Fig. 2. Fructose $P O(1.5 \mathrm{gm} / \mathrm{kg})$ was given after an overnight fast and blood or plasma obtained for $120 \mathrm{~min}$. Upper portion of the curve, reducing substances and true glucose measurements $(\mathrm{mg} / \mathrm{dl})$. Second portion, blood lactate values ( $\mathrm{mM} /$ liter), and the cross-hatched area represents normal measurements. Third portion, free fatty acid levels (mM/liter); crosshatched areas, normal values.
A simultaneous normal rise in plasma growth hormone levels to above $20 \mathrm{ng} / \mathrm{ml}$ was found.

\section{FRUCTOSE LOADING TEST}

The administration PO of fructose failed to increase true glucose values (Fig. 2). Simultaneous blood lactate values were elevated, and the pyruvate levels were reduced thus elevating the $L: P$ ratio. Fructose was presented in the urine after the fructose load.

\section{ETHANOL}

During the 120-min test, plasma glucose values fell only slightly, from 74 to $66 \mathrm{mg} / \mathrm{dl}$ (Fig. 3). Blood lactate values rose to 2.72 $\mathrm{mM} /$ liter.

\section{BLOOD L:P RATIO}

The $L: P$ ratio was frequently greater than the normal $10: 1$ ratio (14), related to a decreased pyruvate level and increased lactate level. This ratio was elevated after glucose, galactose, ethanol, alanine (vide infra), glucagon in the fasted and fed state, and after an overnight fast on 5 separate occasions (Fig. 4).

\section{ADDITIONAL METABOLIC STUDIES}

A second PO glucose load was given followed by measurement of glucose, insulin, alanine, lactate, proline, and glucagon levels. At $180 \mathrm{~min}, 1.0 \mathrm{mg}$ of IM glucagon was given. Glucose intolerance was again found with insulin hyposecretion. Blood lactate values were 1.6 to $2 \mathrm{mM} /$ liter (normal, 1.0 to $1.7 \mathrm{mM}$ ) and fasting
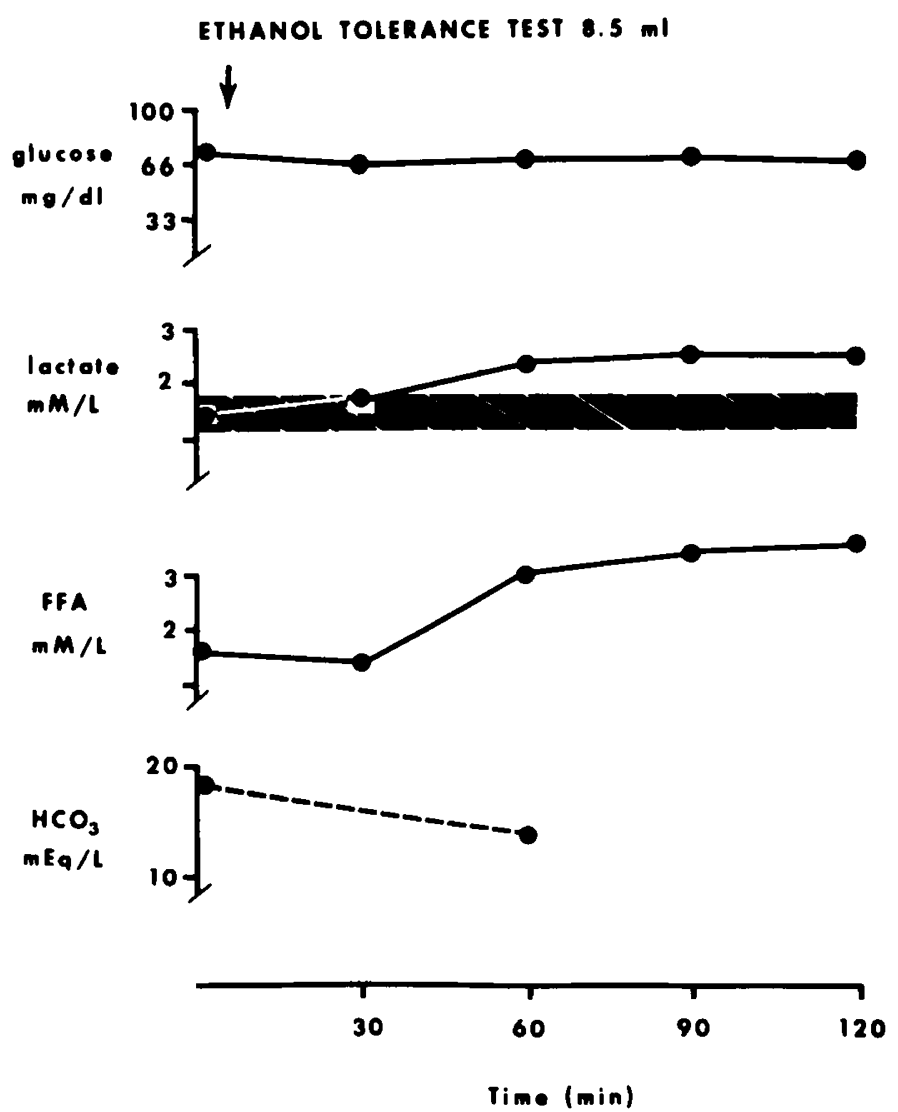

Fig. 3. Ethanol PO $(0.7 \mathrm{ml} / \mathrm{kg})$ was given in a sugar-free base after a 15-hr fast. Blood and plasma were obtained at timed intervals up to 120 $\min$. Top portion, true serum glucose levels $(\mathrm{mg} / \mathrm{dl})$. Second portion, blood lactate values $(\mathrm{mM} / \mathrm{liter})$, cross-hatched area, normal blood levels. The free fatty acid concentration is shown in the third portion of the figure. The plasma bicarbonate concentration ( $\mathrm{mEq} / \mathrm{liter}$ ) is shown in the lower portion of the figure at times zero and $60 \mathrm{~min}$. 
glucagon was elevated at $215 \mathrm{pg} / \mathrm{ml}$ and fell to $140 \mathrm{pg} / \mathrm{ml}$ after glucose administration (normal, $<80 \mathrm{pg} / \mathrm{ml}$ ). There was no fall in plasma alanine, leucine, isoleucine, and proline as is normally seen after a glucose load. When exogenous glucagon was admin-

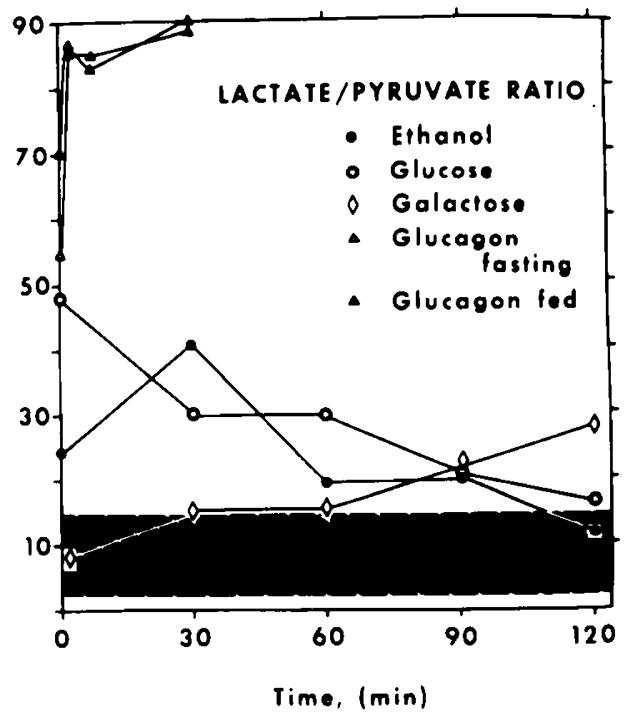

Fig. 4. The L:P ratios obtained at various time intervals after the administration of the following: glucose, galactose, ethanol, and glucagon: and after overnight fasts. Symbols, substance given. Cross-hatched area, range of normal ratios. istered, there was a rise in serum glucose from 43 to $98 \mathrm{mg} / \mathrm{dl}$, but no change in blood lactate, plasma amino acid, or insulin levels (Fig. 5).

Alanine and glycerol PO were administered on separate occasions. Although plasma alanine and glycerol rose, there was again no increase in plasma true glucose values. Peak blood lactate values also rose to 3.01 after alanine and $4.13 \mathrm{mM} /$ liter after glycerol from fasting values of 1.48 and $2.56 \mathrm{mM} /$ liter. Blood pyruvate concentrations were not measured after glycerol administration.

Free fatty acid concentrations were either normal or subnormal and fell after the administration of ethanol, glycerol, fructose, and alanine. Only after ethanol ingestion did plasma free fatty acid levels rise from 0.16 to $0.35 \mathrm{mM} /$ liter. Serum cholesterol and triglyceride values were normal.

Because she failed to convert fructose to glucose, fructose-1,6diphosphatase activity was examined in her leukocytes and was found to be comparable to 2 normal controls.

Glucagon was administered both in the fasted state and $3 \mathrm{hr}$ after being fed a carbohydrate meal, and a differential response in plasma glucose levels was noted (Fig. 6). There was no rise in the fasted state, but glucose rose from 80 to $220 \mathrm{mg} / \mathrm{dl}$ in the fed state. Blood lactate was elevated in both instances to as high as $3.5 \mathrm{mM}$ / liter; pyruvate was reduced.

\section{OPEN LIVER AND MUSCLE BIOPSY}

Except for a cathodal shift in the LDH isozymes, the other studies were normal. The results of the muscle biopsy were also normal (Table 2).

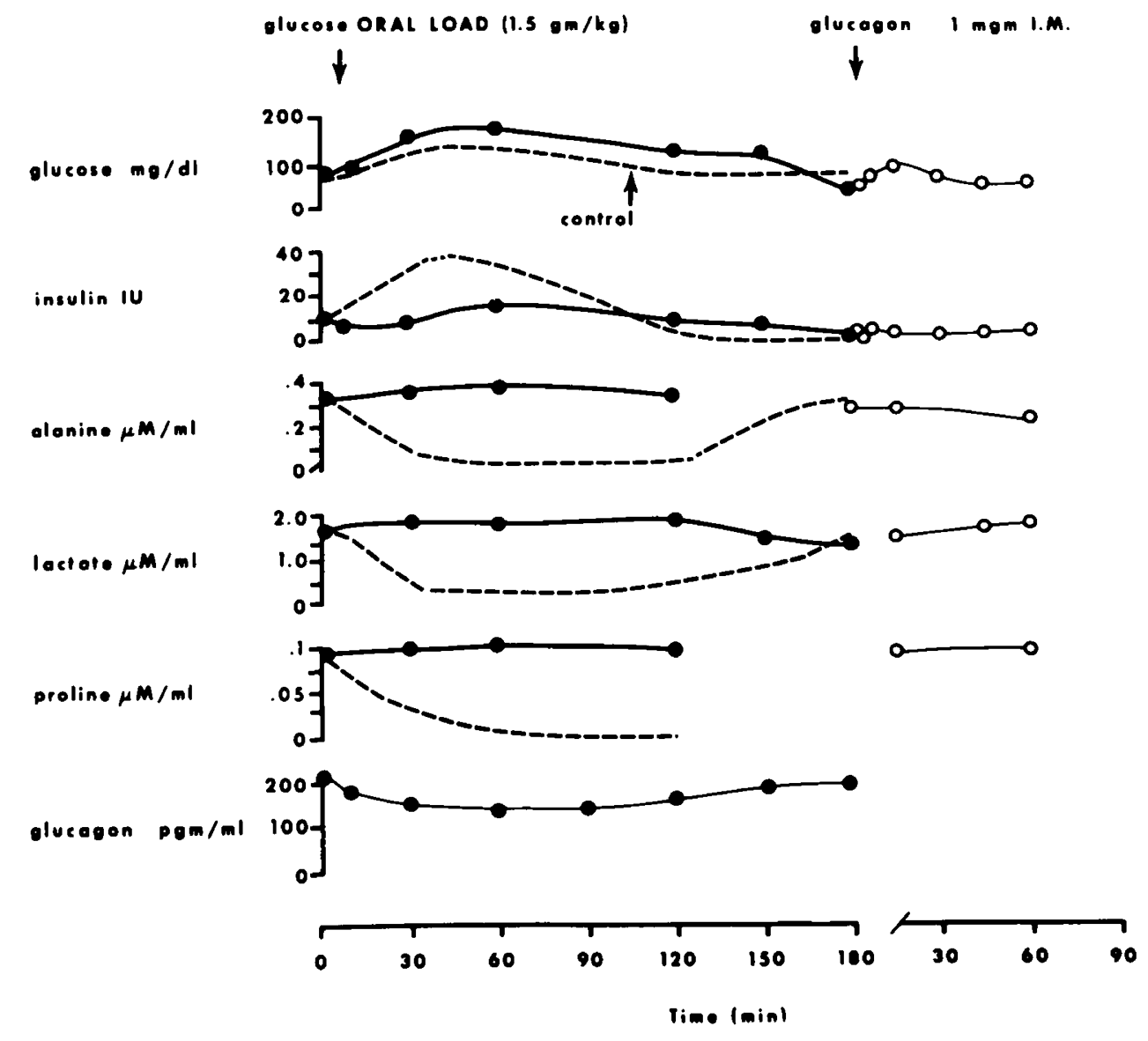

Fig. 5. A PO glucose load $(1.5 \mathrm{~g} / \mathrm{kg})$ was given after an overnight fast. The results of blood or plasma values are shown at various times (min after glucose was given). At $180 \mathrm{~min}$, IM glucagon (I mg) was administered, and repeat measurements were made several times $(\mathrm{min})$ later.
- - - values in a control patient. Upper bar, plasma glucose $(\mathrm{mg} / \mathrm{dl})$. Second line, plasma insulin levels (microunits $/ \mathrm{ml}$ ). Third line, plasma alanine $(\mu \mathrm{M} / \mathrm{ml})$. Fourth line, plasma proline levels $(\mu \mathrm{M} / \mathrm{ml})$, bottom line, plasma glucagon $(\mathrm{pg} / \mathrm{ml})$. $O$, values after glucagon was administered. 


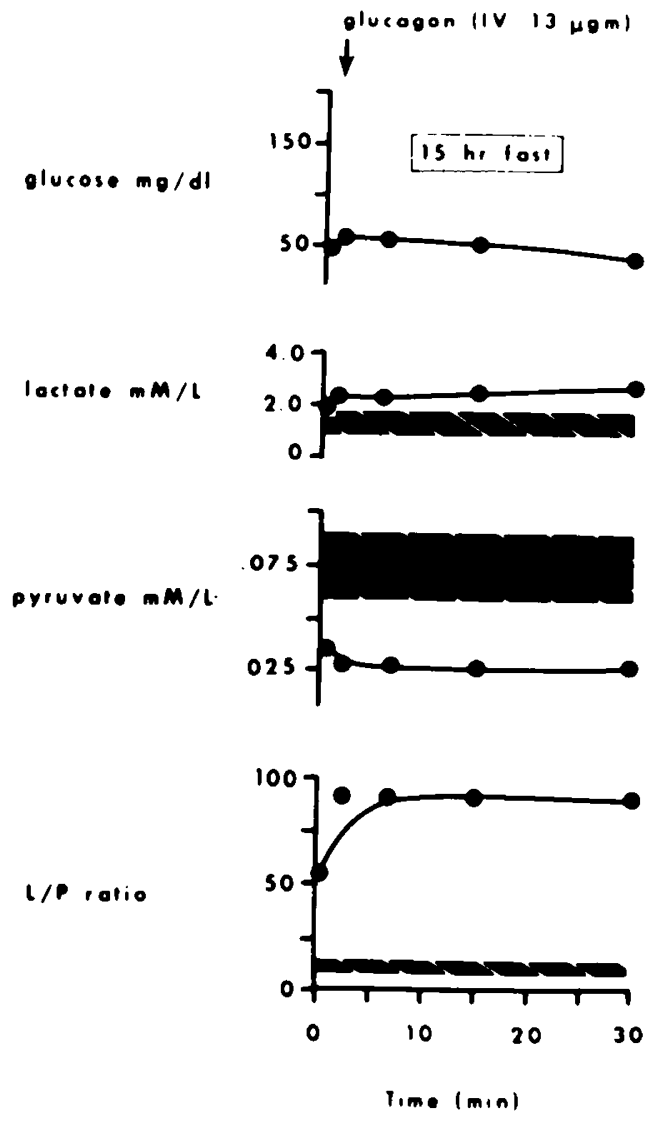

Fig. 6. Glucagon IV $(0.01 \mu \mathrm{g} / \mathrm{kg})$ was given after a $15-\mathrm{hr}$ fast and $2 \mathrm{hr}$ after being fed a carbohydrate meal ( $\mathrm{CHO}=$ carbohydrate). Blood and plasma were obtained at time intervals up to $30 \mathrm{~min}$ after each dose of glucagon. Top portion of the figure, true glucose measurements $(\mathrm{mg} / \mathrm{dl})$.

\section{DISCUSSION}

This patient has the idiopathic Fanconi syndrome of childhood. Of interest are the abnormalities involving carbohydrate metabolism which were much greater than initially suspected. Ketosis and lacticacidemia, first described by McCune et al. (23) in 1943. was an almost consistent finding. She did not have hypokalemia or hypouricacidemia which are usually found in Fanconi syndrome, and her L:P ratio was always abnormal.

Faulty insulin secretion may account for the glucose intolerance found because she responded to low doses of exogenous insulin. Both PO and IV glucose and IM glucagon administration failed to raise plasma insulin levels. These low levels of circulating insulin may be central to the diverse metabolic abnormalities or may represent an epiphenomenon. This insulinopenic "diabeteslike state" with glucose intolerance has also been described in a patient with the Fanconi syndrome associated with hepatic glycogenosis and abnormal galactose metabolism (8). An increased $L: P$ ratio can occur in uncontrolled diabetes $(38)$, but the glucosuria was not a simple diabetic overflow phenomenon. It was clearly the result of proximal renal tubular dysfunction because it occurred at plasma glucose values as low as $40 \mathrm{mg} / \mathrm{dl}$.

Plasma glucagon concentrations were elevated and fell only slightly after glucose administration. Plasma insulin levels were negligible, hence the insulin:glucagon ratio (I:G) was diminished as in diabetes or starvation (41). The constant ketonuria with increased excretion of ketone bodies may be in part related to this inasmuch as a decreased I:G ratio has been associated with an overall net catabolic state and can further augment glucose intolerance.

The failure to convert galactose to glucose has also been described in patients with glycogenosis type I (8), where it is presumably due to glucose-6-phosphatase deficiency. Our patient clearly

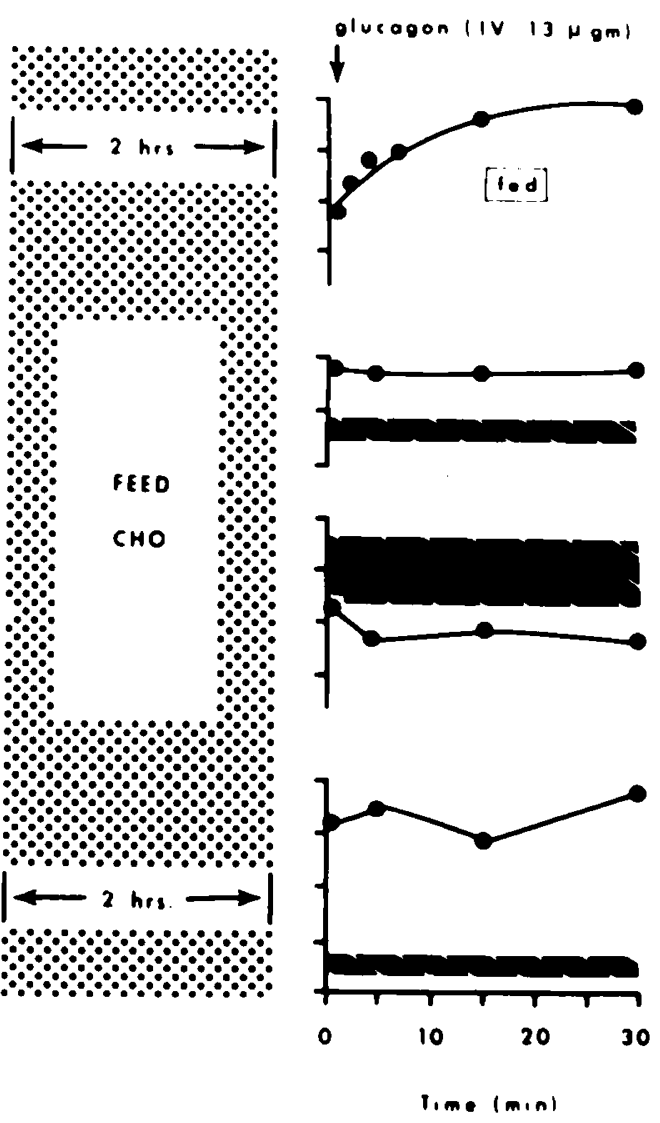

Second portion, blood lactate values ( $\mathrm{mM} /$ liter). Cross-hatched area, normal values. Third portion, blood pyruvate values ( $\mathrm{mM} /$ liter); cross-hatched areas, normal values. Lower portion, L:P ratio; cross-hatched area, normal (5:1 to $15: 1)$ ratio.

did not have the clinical or laboratory findings of glucose-6phosphatase deficiency $(32,36)$. In many respects, she resembled a patient with the Fanconi syndrome who had fasting hyperglycemia, an abnormal glucose tolerance test, attenuated insulin secretion, abnormal galactose tolerance, failure to convert galactose to glucose in vivo, lactic acidosis after a galactose load, and ketonuria (8). However, that patient also had hepatomegaly, marked hypercholesterolemia, hypertriglyceridemia, elevated free fatty acid levels, increased liver glycogen content, and converted fructose to glucose.

Fructosuria occurred only after a PO fructose load. Although fructose was not converted to glucose, she had elevated lactate levels after fructose was given. The serum $\mathrm{PO}_{4}$ concentration was greater than $4.0 \mathrm{mg} / \mathrm{dl}$ prior to fructose loading; however, the serum $\mathrm{PO}_{4}$ level did not fall precipitously after fructose administration as described in patients with hereditary fructose intolerance (7).

There was failure to convert an alanine or glycerol load to glucose. Lactic acidemia with elevated $L: P$ ratios were also noted. This contrasts with many causes of lactic acidosis $(2,3,10,14,21$, $27,28,40)$ in which the normal L:P ratio of $10: 1(14,38)$ tends to be maintained.

The serum alanine concentration usually parallels the rise in blood lactic and pyruvic acid $(21,27)$ but were not elevated in this patient. After the galactose load and after all metabolic studies, lactate rose where pyruvate and alanine did not. These findings could indicate decreased alanine entry into the Krebs cycle via pyruvate conversion to acetyl $\operatorname{CoA}(2,6)$. However, the increased L:P ratio is incompatible with pyruvate dehydrogenase deficiency (10). Thiamine PO (20 to $40 \mathrm{mg}$ daily) produced a transient rise in plasma bicarbonate concentration and a reduction in the daily dose of bicarbonate required to maintain plasma levels of greater than $23 \mathrm{mEq} /$ liter. However, this thiamine-induced effect only 
Table 2. Enzyme Activity in Liver, Muscle, Leukocytes, and Erythrocytes

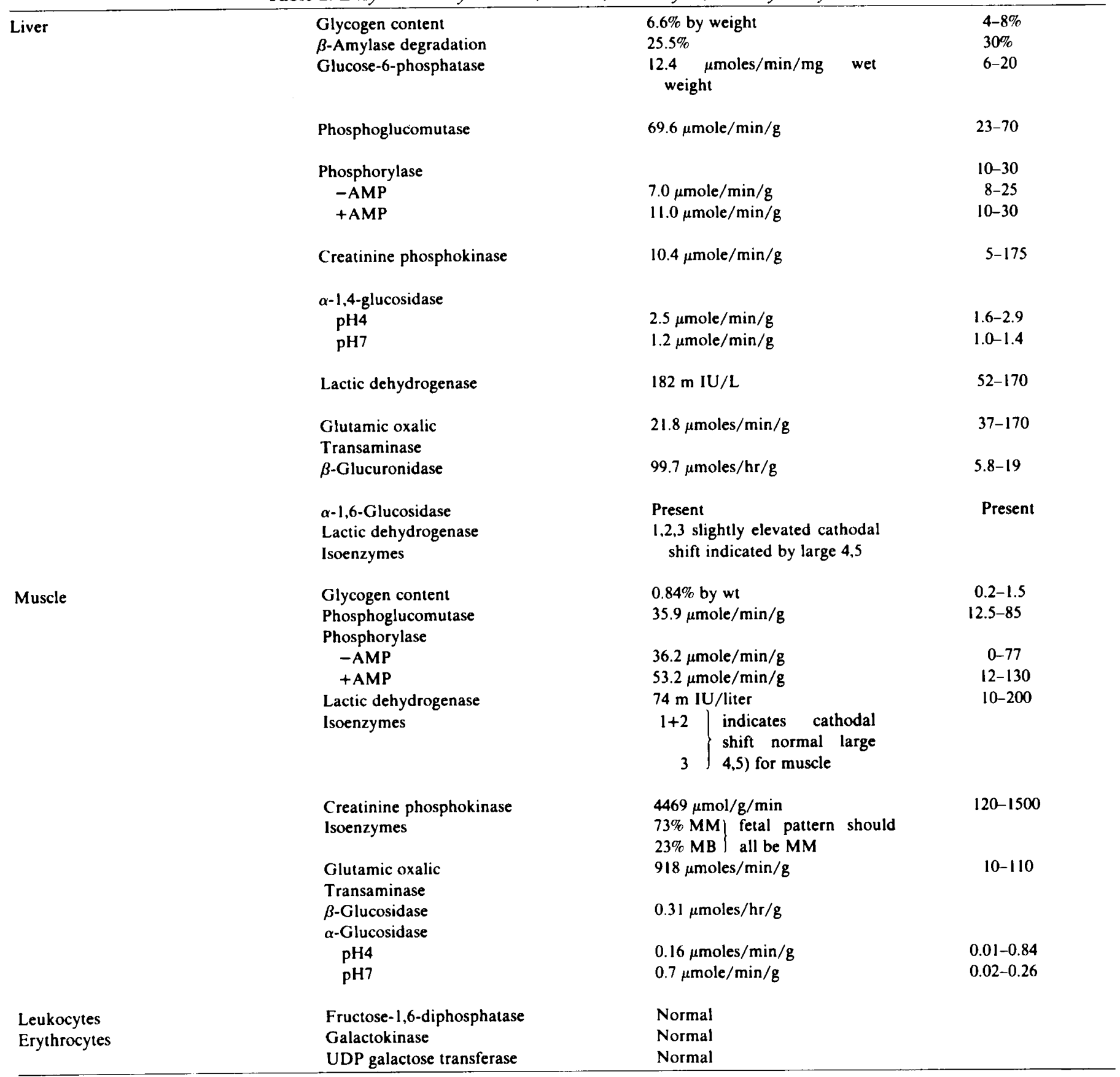

lasted for 8 days. It is possible that this cofactor stimulated transiently the activity of the pyruvate dehydrogenase complex (3). Thiamine $\mathrm{HCl} \mathrm{PO}$ ( $80 \mathrm{mg}$ daily) was then tried for 12 months without effect, which is not surprising in the context of the increased $L: P$ ratios.

Inasmuch as an increased L:P ratio is found in glycogenosis type I and in diabetic ketoacidosis, it is possible that the subnormal insulin secretion present both in glycogenosis type $I(8,36)$ and in our patient is, in part, responsible for the altered ratio. It is also possible that the lack of insulin secretion is a protective mechanism to maintain normal or elevated glucose levels in a patient who cannot make glucose by normal pathways or who loses large amounts in the urine $(1,39)$.

An alternate explanation for the increased L:P ratio which could also explain the diverse metabolic abnormalities is that of an altered cytoplasmic redox state or increased NADH:NAD ${ }^{+}$ ratio $(16,38)$. This would result in the shifting of certain NADH:
$\mathrm{NAD}^{+}$coupled metabolic reactions to the reduced state, including the L:P ratio $(16,42)$. Furthermore, an elevated cytoplasmic or mitochondrial NADH:NAD ${ }^{+}$ratio would lead to inhibition of galactose conversion to glucose (because $\mathrm{NAD}^{+}$is required for UDPG epimerase activity), pyruvate conversion to acetyl-CoA, and Krebs cycle oxidative activity (16). The failure of the conversion of alanine, fructose, or glycerol to glucose in vivo could be the result of NADH inhibition of the pathways resulting in glucose synthesis. Moreover, all these compounds would be converted to lactate and possibly pyruvate levels would fall. The effect of an increased NADH:NAD ${ }^{+}$ratio or altered intracellular redox state could also favor the flow of glucose into glycerol-3-phosphate and in turn triglyceride synthesis (16). Carbon would thus proceed from the glycolytic pathway into lipid metabolism. After ethanol administration which would further increase NADH production (32), plasma free fatty acid levels did indeed rise. As these fats are utilized, ketone bodies would be formed. and this would be a 
further indication of decreased Krebs cycle activity. Thus, an altered redox state could be the central defect in this patient and perhaps in other atypical forms of the Fanconi syndrome $(8,17$, 20).

\section{REFERENCES AND NOTES}

I. Berman. B. G.. and Halperin. M. L.: Effect of insulin on pyruvate metabolism in epididymal adipose tissue of rat. Correlation of intracellular pyruvate contents and pyruvate dehydrogenase activity. Biochem. J.. 134: 885 (1973).

2. Blass. J. P.. Avigan. J.. and Uhlendorf. B. W.: A defect in pyruvate decarboxylase in a child with an intermittent movement disorder. J. Clin. Invest., 49: 423 (1970).

3. Brunette. M. G.. Delvin, E., Hazel, B., and Scriver, C. R.: Thiamine responsive lactic acidosis in a patient with deficient low- $\mathrm{Km}$ pyruvate carboxylase activity in liver. Pediatrics, 50: 702 (1972).

4. Chodirker. W. B.. Bock. G. N., and Vaughan, J. H.: Isolation of human PMN leukocytes and granules: observations on carly blood dilution and on heparin. J. Lab. Clin. Med.. 71: 9 (1968).

5. Dent. C. E.: A study of the behavior of some sixty aminoacids and other ninhydrin reacting substances on phenol-collidine filter paper chromatograms with notes as to the occurrence of some of them in biological fluids. Biochem. J. $43 \cdot 169$ (1948).

6. Falk. R. E., Cederbaum, S. D., Blass, J. P., Pruss, F. J., and Carrel. R. E.: Clinical and biochemical response to a ketogenic diet in two brothers with pyruvate dehydrogenase deficiency. Pediatr. Res. (Abstract), 9: 350 (1975).

7. Froesch. E. R.. Wolf, H. P.. Baitsch. H.. Prader. A.. and Lubhar. A.: Hereditary iructose intolerance. An inborn defect of hepatic fructose-1-phosphate splitting aldolase. Am. J. Med.. 34: 151 (1963).

8. Garty. R., Cooper. M., and Tabachnik. E.: The Fanconi syndrome associated with hepatic glycogenosis and abnormal metabolism of galactose. J. Pediatr. 85: 821 (1974).

9. Goldman. H., Scriver. C. R., Aaron. K., Delvin. E., and Canlas, Z.: Adolescent cystinosis: comparisons with infantile and adult forms. Pediatrics, 47: 979 (197!).

10. Gruskin. A. B., Patel. M. S.. Linshaw. M.. Ettenger. R., Huff, D., and Grover. W.: Renal function studies and kidney pyruvate carboxylase in subacute necrotizing encephalomyelopathy (Leigh's syndrome). Pediatr. Res.. 7: 832 (1973)

11. Hers, H. G.: Etudes enzymatiques sur fragments hepatique. Application a la classification des glycogenoses. Rev. Int. Hepatol.. 9: 35 (1959).

12. Hillman, D. A.. and Colle. E.: Plasma growth hormone and insulin responses in short children. Am. J. Dis. Child., I17: 636 (1969).

13. Hoffman, W. S.: A rapid photoelectric method for the determination of glucose in blood and urine. J. Biol. Chem., 120: 51 (1937).

14. Huckabee. W. E.: Relationships of pyruvate and lactate in hypoxia. J. Clin. Invest.. 37: 244 (1958).

15. Hyvarinen. A.. and Nikkila. E. A.: The analysis of glucose and other sugars by $O$-Toluidine reduction. Clin. Chem.. 9: 234 (1963).

16. Krebs. H. A.: Role of the redox state of nicotinamide adenine dinucleotides in the regulation of metabolic processes. Natl. Cancer Inst. Monogr.. 27: 331 (1967).

17. Lampert, F., Mayer, H., Tocci, P. M., and Nyhan, W. L.: Fanconi Syndrome in glycogen storage disease. In: W. L. Nyhan: Amino Acid Metabolism and Genetic Variation. pp. 353-365 (McGraw-Hill, New York, 1967)

18. Laurell, S., and Tibbling, G.: Colorimetric micro-determination of free fatty acids in plasma. Clin. Chim. Acta., 16: 57 (1967).

19. Leaf, A.: The Syndrome of Osteomalacia. Renal Glycosuria, Aminoaciduria, and Increased Phosphorus Clearance (The Fanconi Syndrome). In: J. B. Stanbury, J. B. Wyngaarden, D. S. Frederickson: The Metabolic Basis of Inherited Disease. 2nd ed pp. 1205-1229 (McGraw-Hill Book Co.. New York. 1966).

20. Linder, G. C.. Bull. B. M.. and Grayer. I.: Hypophosphatemic glycosuric rickets (Fanconi Syndrome). I. A study of the acid base balance and aminoacid excretion. Report of a case with retinitis pigmentosa. Clin. Proc. J. Cape Town Post-Grad Med Assn. 8:1 (1949)

21. Lonsdale. D.. Faulkner. W. R.. Price. J. W.. and Smeby, R. R.: Intermittent cerebellar ataxia associated with hyperpyruvic acidemia, hyperphenylalaninemia. and hyperalaninuria. Pediatrics. 43: 1025 (1969).

22. Mamer. O. A.. Crawhall. J. C., and Tjoa, S. S.: The identification of urinary acids by coupled gas chromatography-mass spectrometry. Clin. Chim. Acta. 32: 171 (1971).

23. McCune. D. J., Mason, H. H., and Clarke, H. T.: Intractable hypophosphatemic rickets with renal glycosuria and acidosis (The Fanconi Syndrome). Am. Dis. Child. 65: 81 (1943).

Copyright (c) 1980 International Pediatric Research Foundation. Inc. $0031-3998 / 80 / 1403-0209 \$ 02.00 / 0$
24. McSherry, E., Sebastian. A., and Morris, R. C., Jr.: Renal tubular acidosis in infants: the several kinds, including bicarbonate-wasting, classical renal tubular acidosis. J. Clin. Invest.. 51: 499 (1972).

25. Melancon, S. B., Khachadurian, A. K., Nadler, H. L., and Brown, B. I.: Metabolic and biochemical studies in fructose 1.6-diphosphatase deficiency. J. Pediatr. 82: 650 (1973).

26. Mohyuddin. F., and Scriver. C. R.: Amino acid transport in mammalian kidney: multiple systems for amino acids and glycine in rat kidney. Am. J. Physiol. 219:1 (1970).

27. Pagliara. A. S., Karl, 1. E.. DeVivo, D. C., Feigin, R. D., and Kipnis, D. M. Hypoalaninemia: a concomitant of ketotic hypoglycemia. J. Clin. Invest., SI: 1440 (1972).

28. Pagliara. A. S.. Karl. 1. E.. Keating. J. P., Brown. B. 1., and Kipnis. D. M.: Hepatic fructose-1.6-diphosphatase deficiency. A cause of lactic acidosis and hypoglycemia in infancy. J. Clin. Invest.. SI: 2115 (1972).

29. Rodriquez-Soriano, J., and Edeimann. C. M.. Jr.: Renal tubular acidosis. Ann Rev. Med., 20: 363 (1969).

30. Roe. C. R., Limbird, L. E.. Wagner, G. S. and Nerenberg. T. S.: Combined isoenzyme analysis in the diagnosis of myocardial injury: application of electrophoretic methods for the detection and quantitation of the creative phosphokinase MB isoenzyme. J. Lab. Clin. Med., 80: 577 (1972).

31. Rosenberg. J. C., and Rush, B. F.: An enzymatic-spectrophotometric determination of pyruvic and lactic acid in blood. Methodologic aspects. Clin. Chem., 12: 299 (1966).

32. Sadeghi-Nejad, A., Hochman, H., and Senior, B.: Studies in type I glycogenosis: the paradoxical effect of ethanol on lactate. J. Pediatr., 86: 37 (1975).

33. Schneider, J. A., and Seegmiller, J. E.: Cystinosis and the Fanconi Syndrome. In: J. B. Stanbury, J. B. Wyngaarden, D. S. Fredrickson: The Metabolic Basis of Inherited Disease. 3rd ed. Chap. 67. pp. 1581-1596 (McGraw-Hill Book Co., New York, 1972).

34. Scriver. C. R.. Davies, E., and Lamm. P.: Accelerated selective short column chromatography of neutral and acidic aminoacids on a Beckman-Spinco Analyzer, modified for simultaneous analysis of two samples. Clin. Biochem. I: 179 (1968)

35. Scriver. C. R.. and Rosenberg. L. E.: Methods of analysis and diagnosis of aminoacidopathies, In Amino Acid Metabolism and Its Disorders, Chap. 5 , pp. 95-139. (W. B. Saunders. Toronto, 1973).

36. Segal, S. E.: Disorders of galactose metabolism. In: J. B. Stanbury, J. B. Wyngaarden, D. S. Fredrickson: The Metabolic Basis of Inherited Disease. 3rd ed. pp. 174-195. (McGraw-Hill, New York, 1972).

37. Senior, B.. and Loridan. L.: Functional differentiation of glycogenoses of the liver with respect to the use of glycerol. N. Engl. J. Med., 279: 965 (1968).

38. Shapiro. H. M.: Redox balance in the body: an approach to quantitation. J. Surg Res.. 13: 138 (1972)

39. Taylor, S. I., Mukherjee. C., and Jungas, R. L.: Studies on the mechanism of activation of adipose tissue pyruvate dehydrogenase by insulin. J. Biol. Chem. 248: 73 (1973)

40. Tildon, J. T., and Cornblath. M.: Succinyl-CoA: 3-ketoacid CoA-transferase deficiency. A cause for ketoacidosis in infancy. J Clin. Invest. 51:493 (1972).

41. Unger. R. H.: Glucagon and the insulin: glucagon ration in diabetes and other catabolic illnesses. Diabetes, 20: 834 (1971).

42. Wieland, O., and Loemer. G.: Uber den Mechanismus der gesteigerten Ketonkorperbildung. I. Redox-Status des Leber-DPN unter Ketose-bedingunger in vivo. Biochem. Z. 339: 204 (1963).

43. This work was presented in part at the Annual Meeting. 1975 Midwest Society for Pediatric Research. (J. Pediatr.. 88: 683. 1976).

44. The expert assistance of Jacqueline Rioux and Terry Reade in performing these studies is gratefully acknowledged. We thank Orval Mamer. Ph.D., for performing GLC-Mass spectroscopic studies, James Sidbury. M.D. for assays of hepatic and muscle enzymes. and Serge Melancon, M.D. for assays of leukocyte fructose-1,6-diphosphatase activity. The advice of Drs. Peter Whitington. Steven Cederbaum. and David Simpson is gratefully acknowledged. We appreciate the efforts of Kathleen 'henoweth-Corby. Mailyn Woo, and Anna Fisher who helped in the preparation of the manuscript.

45. Requests for reprints should be addressed to: R. W. Chesney, M.D., Department of Pediatrics, University of Wisconsin, University Avenue, Madison, Wisconsin 53706 (USA).

46. This research was supported by grants from the Medical Research Council of Canada (Group Grant in Medical Genetics. MT-1579, E-50). The Montreal Children's Hospital Research Institule, and the Quebec Network for Genetic Screening.

47. Received for publication December 14, 1978.

48. Accepted for publication May 23, 1979. 